\title{
Defective Monocyte Chemotaxis in Children with Down's Syndrome
}

\author{
O. BARROETA, L. NUNGARAY, M. LÓPEZ-OSUNA, S. ARMENDARES, F. SALAMANCA, AND \\ R. R. KRETSCHMER ${ }^{(38)}$ \\ Divisions of Immunology and Human Genetics, Unidad de Investigación Científica, Centro Medico Nacional, \\ I.M.S.S. Mexico City, Mexico
}

\begin{abstract}
Summary
Under-agarose random migration, chemokinesis and chemotaxis of monocytes from 36 patients with Down's syndrome were compared to those of monocytes from 42 healthy, age-matched control children. Random migration of monocytes from patients with Down's syndrome was comparable to that of controls. In contrast, chemotaxis of monocytes from patients with Down's syndrome was significantly decreased $(P<0.001)$ when compared to that of controls, even though chemokinesis was significantly increased $(P$ $<0.001$ ). Age, sex, and physical development of patients with Down's syndrome or of control children included in this study had no apparent effect upon monocyte mobility.
\end{abstract}

\section{Abbreviations}

CS, control serum

DS, Down's syndrome

MP, mononuclear phagocytes

ZAS, zymosan-activated serum

Increased susceptibility to infection in patients with DS $(22,28)$ may reflect several abnormalities in host defense mechanisms involving humoral and cellular immune responses $(2,17)$ and the inflammatory-phagocytic process $(13,15,27)$. No defect can be singled out as the most important one, hence the definition of the immunodeficiency of DS as a complex sum of several immunologic faults of variable intensity that can change with age (4). Cellmediated immunity in DS is predominantly impaired at its effector site (34): depressed in vitro lymphocyte responses, anergy or weak delayed type hypersensitivity skin reactions and decrease in circulating $T$ cells have been reported in patients with DS $(16,17)$, although lymphocytosis with high counts of $\mathrm{T}$ and $\mathrm{B}$ cells may be found in older, institutionalized patients (34).

MP and lymphocytes constitute the bulk of the inflammatory cells in delayed hypersensitivity reactions, MP playing a crucial role in phagocytosis as well (5). Accumulation of mononuclear cells at such inflammatory sites depends largely on their response to chemotactic signals. Poor mobilization of these cells may contribute to the weakness of delayed hypersensitivity and other inflammatory reactions in DS (6). We measured random migration, chemokinesis (enhancement of random migration) and chemotaxis (directional migration) of MP from patients with DS and compared them to those of healthy age-matched children. We employed the agarose-plate method (21), which is less expensive, simpler, and more reproducible than the Boyden chamber method, even though the relative sensitivity of the two assays is still somewhat controversial $(14,19)$. Only MP of a mononuclear leukocytes population seem to contribute to the migration pattern using the agarose device (21).

\section{MATERIALS AND METHODS}

Patients and controls. Thirty-six home-cared patients with DS (Trisomy 21: 14 females, 22 males, 6 months to 7 years of age) were studied. None of the patients had leukemia, suffered of overt infection or took any medication within $2 \mathrm{wk}$ of the study. Fortytwo healthy children ( 15 females, 27 males, 6 months to 7 years of age) undergoing elective orthopaedic surgery, and matched as closely as possible with the patients for similar age and sex were used as controls. Differential blood counts performed before the study were normal and comparable in patients and controls. The children were further subdivided according to their physical development (25) to ascertain the effect of this parameter upon MP locomotion. Written consent was obtained from fully informed parents or guardians in all cases.

Preparation of cells. Five $\mathrm{ml}$ of fasting heparinized (10 units of sodium heparin $/ \mathrm{ml}$ of blood) venous blood were obtained between 8 and 9 AM in all cases. Mononuclear cells were isolated on a Ficoll (Sigma Chemical Co., St. Louis, MO) Hypaque (Winthrop Labs., Mexico) gradient following the method of Böyum (3). Cells were washed three times with RPMI-1640 medium (Gibco, Long Island, NY) and were resuspended in the same medium to a concentration of $10^{8}$ cells $/ \mathrm{ml}$. In both patients with DS and controls, $30 \pm 5 \%$ of these cells were MP and the rest were lymphocytes using Wright and confirmatory peroxidase and $\mathrm{Na}$ phtol AS-D chloroacetate esterase stains for cell differentiation (23). Cell viability was above $95 \%$ by trypan blue dye exclusion.

Production of chemotactic and chemokinetic factors. A single batch, pooled (10 donors) human fresh $\mathrm{AB} R \mathrm{Rh}+$ serum (kept frozen in $3-\mathrm{ml}$ aliquots at $-70^{\circ} \mathrm{C}$ until used) was used throughout the experiment. On the day of the experiment two aliquots were thawed in a water bath at $37^{\circ} \mathrm{C}$ and $4 \mathrm{mg}$ of zymosan per $\mathrm{ml}$ (Sigma Chemical Co., St. Louis, Mo) were added to one of the samples and processed by the method of Ward (33) [ZAS]. CS was prepared by heating the second serum aliquot at $56^{\circ} \mathrm{C}$ for 30 min before the addition of zymosan.

Preparation of agarose plates. The chemotaxis-under-agarose method as described by Nelson et al. (21) was employed using 60 $\times 15 \mathrm{~mm}$ plastic tissue culture dishes (3002, Falcon, Oxnard, CA) and $10 \%$ human albumin added to the $5 \mathrm{ml}$ agarose (Sigma Chemical Co., St. Louis, MO) of each plate. For the chemokinetic assays, $1.6 \mathrm{ml}$ of ZAS or CS was homogeneously added to the agarose. For the chemotactic assays six series of three radially disposed wells, $3.0 \mathrm{~mm}$ in diameter and spaced $3.0 \mathrm{~mm}$ apart, were cut into each plate using an ad hoc plexiglass template. For the chemokinetic assays, six hexagonally arranged wells, spaced 10 $\mathrm{mm}$ apart, were cut in each plate using the same plexiglass template. The resulting agarose plugs were carefully removed using a hypodermic needle.

Chemotaxis. The center well of each three-well series received $10 \mu 1$ of the cell suspension, the inner well $10 \mu 1$ of ZAS and the outer well $10 \mu \mathrm{l}$ of CS. The dishes were incubated on a level platform for $18 \mathrm{~h}$ at $37^{\circ} \mathrm{C}$ in a humidified atmosphere containing $5 \% \mathrm{CO}_{2}$ in air. Cells were fixed with the agarose in place by the addition of $3 \mathrm{ml}$ of absolute methanol for $30 \mathrm{~min}$ followed by 30 $\mathrm{min}$ in $3 \mathrm{ml}$ of $47 \%$ buffered formalin. The gel was removed intact after fixation and the dishes were gently washed with phosphate buffered saline $\mathrm{pH} 7.4$, stained with Wright's stain and air dried. Some plates were also peroxidase-stained for cell evaluation (23). 
The migration patterns were projected onto a white background using a photographic amplifier (Beseler, East Orange, NJ) so that the diameter of the projected wells measured exactly $2.0 \mathrm{~cm}$. Migration was quantitated by measuring (in $\mathrm{mm}$ ) the distance the leading front of the cells had moved from the margin of the well towards the well containing ZAS (distance $\mathrm{A}=$ chemotaxis), or towards the well containing $\mathrm{CS}$ (distance $\mathrm{B}=$ random migration) along a line crossing the center of the three wells. Each cell sample was assayed by triplicate, the measurements were averaged, and the chemotactic index (A/B) was calculated for each cell sample (21).

Chemokinesis. Each well on the chemokinetic plates received 10 $\mu \mathrm{l}$ of the cell suspension. Incubation, fixation, staining, and amplification proceeded then as in the chemotactic assays. Regular rings of cell migration were formed around the wells, and the distance from the margin of the well to the cell front moving outside along the radius of the plate running through the center of the well was measured. Each cell sample was assayed by triplicate, the results were averaged, and the chemokinetic index (migration in ZAS-containing agarose/migration in CS-containing agarose) was calculated (31).

Statistical analysis. The Pittman test was used for nonparametric statistical analysis of the results (29).

\section{RESULTS}

Random migration of MP from patients with DS $(3.4 \pm 1.0$ $\mathrm{mm}$ ) was comparable to that of MP from control children (3.6 \pm $1.0 \mathrm{~mm}$ ) (Fig. 1). On the other hand the chemokinetic index of MP from patients with DS $(2.2 \pm 0.2)$ was significantly $(P<$ $0.001)$ higher than that of MP from control children $(1.8 \pm 0.3)$. In contrast, the chemotactic index of MP from patients with DS $(1.2 \pm 0.1)$ was significantly decreased $(P<0.001)$ when compared to that of MP from control children $(1.5 \pm 0.2)$. Migrating cells, both in the chemokinetic and the chemotactic assays consisted primarily of MP, the lymphocytes remaining within the confines of the well and as a small and regular rim at the agarose edge of the well.

Physical development of patients with DS or control children had no apparent effect upon MP random migration, chemokinesis, or chemotaxis (the latter shown in Fig. 2), nor was there any correlation between these cell-mobility parameters and age or sex of the subjects included in this study. Furthermore there were no differences in physical development, age, or sex regarding the numerous overlapping DS and control subjects found in the chemokinesis and chemotaxis results.

\section{DISCUSSION}

Chemotaxis-under-agarose of MP from patients with DS towards complement-derived chemotactic factors (ZAS) was significantly decreased when compared to that of MP from normal agematched children. In contrast, random migration of MP from patients with DS was comparable to that of MP from normal children and chemokinesis was even increased with respect to MP of normal children. A similar defect in chemotaxis, in the face of normal random mobility, was found not only by Khan et al. (13) studying neutrophils from patients with DS using Boyden chambers, although chemokinesis was not evaluated in their experiments, but also by Björkstén et al. (2) who only reported neutrophil chemotaxis in their study. These results suggest that the chemotactic defect observed in leukocytes from patients with DS may be a cellular one because the chemotactic signal (ZAS) was the same and adequate in these three studies. The possibility of an inhibitor of chemotaxis tightly bound to the cells cannot be ruled out, although the thorough washing of the cells appears to argue against this hypothesis. Furthermore, our study and that of Khan et al. (13) also support the concept that chemotaxis and random mobility (and its enhanced version, chemokinesis) can operate independently from each other (35). That the chemokinetic indices exceeded the chemotactic indices in our study is a striking, yet not

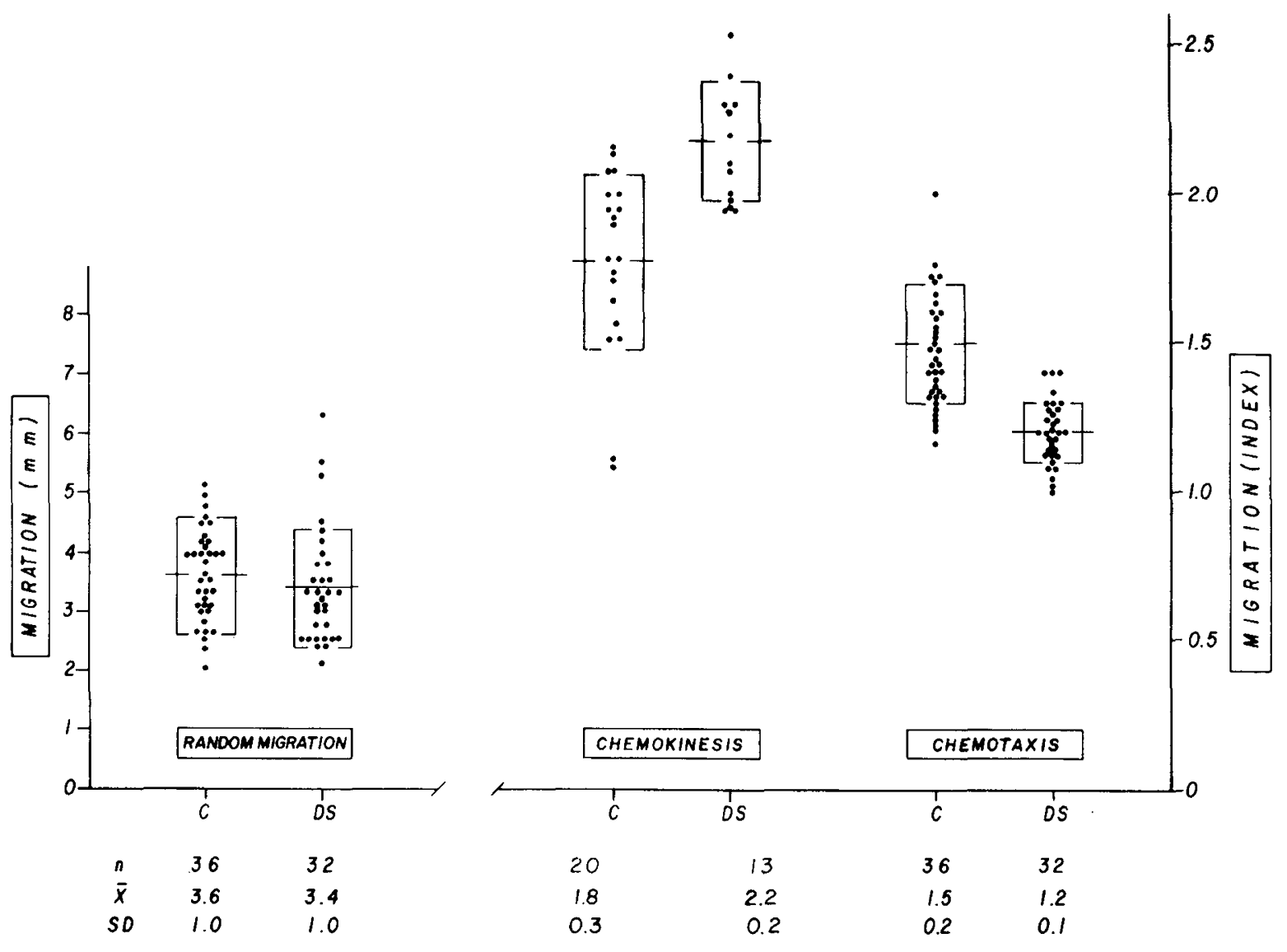

Fig. 1. Random migration, chemokinesis, and chemotaxis of monocytes from patients with Down's syndrome (DS) and healthy control children (C). Individual values, mean and \pm 1 S.D. are shown in the figure. $n$, number of cases; $\bar{X}$, mean; and S.D., standard deviation. 


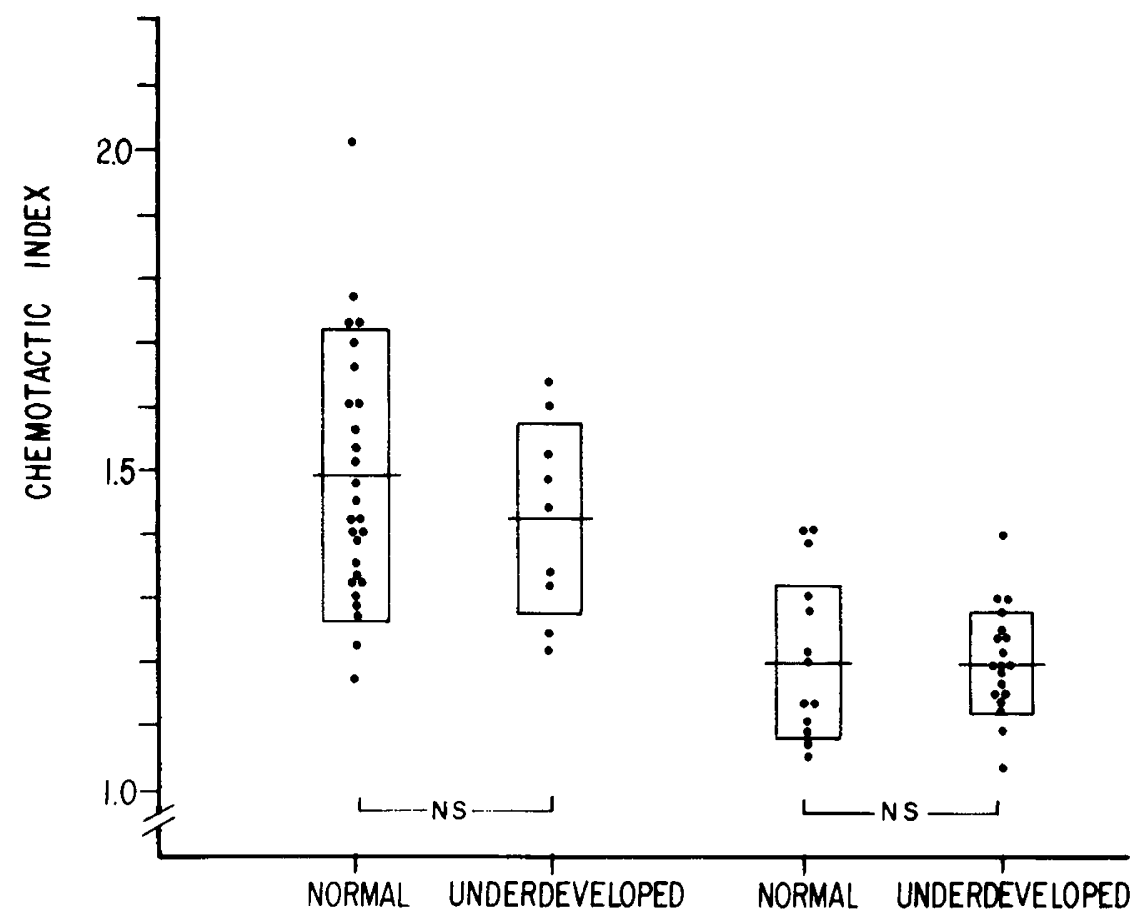

\section{CONTROLS}

\section{DOWN'S SYNDROME}

Fig. 2. Chemotactic index of monocytes from children with Down's syndrome and healthy controls subdivided by their physical development (see reference no. 25). Normal, weight/height, weight/age, and height/age ratios within 2.5 standard deviations from the mean. Underdeveloped, weight/ height, weight/age, and height/age ratios below 2.5 standard deviations from the mean. Individual values, mean and \pm 1 S.D. are shown. N.S./ not significant

a totally unexpected observation in under-agarose cell-mobility studies $(7,31)$.

The assays were performed with a mixture of MP and lymphocytes, but our results reflect primarily MP chemotaxis because the lymphocytes, although mobile in Boyden chambers towards C5a (8), apparently do not enter far enough the narrow space beween the agarose and the bottom of the plastic dish (21).

This defect in MP chemotaxis in patients with DS may contribute not only to their increased susceptibility to infections, particularly of the respiratory tract $(22,28)$, but may explain other immunologic abnormalities as well. The MP plays an important role in both the afferent and the efferent pathways of the immune response (5). In both functions prompt arrival at the critical scene is essential. Poor MP migration may compromise the complex cell interactions required for antibody production $(26,32)$, and patients with DS have been repeatedly shown to have abnormal antibody responses to some antigens (18), although their $\operatorname{IgG}$ and IgA levels may be normal or high and their IgM levels normal or somewhat diminished $(27,30)$. Impaired MP chemotaxis, even in the face of increased chemokinesis, may also contribute to the abnormal delayed hypersensitivity skin reactions observed in patients with DS $(16,17)$. Chemotactic signals more relevant to such reactions (i.e., lymphocyte derived chemotactic factor) (1) remain, however, to be evaluated.

The nature of the chemotactic defect in leucocytes of patients with DS is not clear, but may be tentatively attributed to intrinsic cellular abnormalities $(11,12,20,24,36)$, or shifts in the migrating subpopulations of leukocytes (9). Defective leukocyte chemotaxis in another chromosomopathy, namely monosomy-7, has been related to a decrease in high molecular weight surface glycoproteins (10).

Age, sex, or physical development did not seem to influence MP mobility in our study. With respect to age, our results seem to be at variance with those of Klein et al. (14), who found that MP under-agarose chemotaxis in normal children was clearly age- dependent, with values increasing with age. But their population age-range was wider than ours and the age-dependent effect upon chemotaxis was more noticeable from 6 years onward, yet our oldest patients were only 7 years old.

In conclusion, the MP chemotactic defect, by diminishing the rapidity and quality of inflammatory reactions and therefore the efficiency of cell interactions in immune responses, may contribute to the increased susceptibility to infection in patients with DS.

\section{REFERENCES AND NOTES}

1. Altman, L. C., Snyderman, R., Oppenheim, J. J., and Mergenhagen, S. E. A human mononuclear leukocyte chemotactic factor: characterization, specificity and kinetics of production by homologous leukocytes. J. Immunol., 110: 801 (1973).

2. Björkstén, B., Bäck, O., Hägglof, B. and Tärnvik, A.: Immune function in Down's syndrome. In: F. Guttler, J. W. T. Seakins and R. A. Harkness, Eds.: Inborn Errors of Immunity and Phagocytosis. pp. 189-198 (University Park Press, Baltimore, MD (1979).

3. Böyum, A.: Isolation of mononuclear cells and granulocytes from human blood. Scand. J. Clin. Lab. Invest., 21 (Suppl. 97): 77 (1968).

4. Burgio, G. R. and Ugazio, A. G.: Das Down-Syndrom als Immunmangel-Modell. Ergebnisse und Hypothesen. Helv. Paediatr. Acta, 33: 5 (1978)

5. Cline, M. J., Lehrer, R. I., Territo, M. C.; and-Golde. D.-W.: Monocytes and macrophages: functions and diseases. Ann. Int. Med., 88: 78 (1978)

6. Dannenberg. A.M.: Macrophages in inflammation and infection. N. Engl. J. Med., 293: 489 (1975).

7. Dohlman, J. G. and Goetzl, E. J.: Unique determinants of alveolar macrophage spontaneous and chemokinetically stimulated migration. Cell Immunol., 39: 36 (1978).

8. El-Naggar, A. K., Van Epps, D. E., and Williams, R. C.: Human-B and Tlymphocyte locomotion in response to casein. C5a, and $\mathrm{f}-\mathrm{Met}-\mathrm{Leu}-\mathrm{Phe}$. Cell Immunol.. 56: 365 (1980).

9. Falk, W. and Leonard, E. J.: Human monocyte chemotaxis: migrating cells are a subpopulation with multiple chemotaxis specificities on each cell. Infect. Immun.. 29: 953 (1980).

10. Gahmberg, C. G., Andersson, L. C., Ruutu, P., Timonen, T. T. T., Hanninen, A.. Voupio, P., and DeLaChapelle, A.: Decrease of the mayor high molecular weight surface glycoprotein of human granulocytes in monosomy-7 associated with defective chemotaxis. Blood, 54: 401 (1979).

11. Gallin, J. I., Wright, D. G., Malech, H. L., Davis. J. M.. Klempner, S. S., and 
Kirkpatrick, C. H.: Disorders of phagocyte chemotaxis. Ann. Int. Med., 92: 520 (1980)

12. Hsia, D. Y. Y., Justice, P., George, F., Smith, G. F., and Dowben, R. M.: Down's syndrome. A critical review of the biochemical and immunological data. Am J. Dis. Child., I21: 153 (1971)

13. Khan, A. J., Evans, H. E., Glass, L., Yong. H. S., and Almonte, D.: Defective neutrophil chemotaxis in patients with Down syndrome. J. Pediatr., 87: 87 (1975)

14. Klein, R. B., Fischer, T. J., Gard, S. E., Biberstein, M., Rich, K., and Stiehm, R. E.: Decreased mononuclear and polymorphonuclear chemotaxis in human newborn infants and young children. Pediatrics, 60: 467 (1977).

15. Kretschmer, R. R., López-Osuna, M., De la Rosa, L., and Armendares, S. Leucocyte function in Down's syndrome. Quantitative NBT reduction and bactericidal capacity. Clin. Immunol. Immunopathol., 2: 449 (1974).

16. Levin, S., Nir, E., and Mogilner, B. M.: T-system immune-deficiency in Down's syndrome. Pediatrics, 56: 123 (1975.

17. Levin, S., Schlesinger, M., Handzel, Z., Hahn, T., Altman, Y., Czernobilsky, B., and Boss, J.: Thymic deficiency in Down's syndrome. Pediatrics, 63: 80 (1979).

18. Lopez, V., Ochs, H., Thuline, H. C., Davis, S. D., and Wedgewood, R.: Defective antibody response to bacteriophage $\emptyset \mathrm{X} 174$ in Down syndrome. J. Pediatr., 86: 207 (1975).

19. Maderazo, E. G. and Ward, P. A.: Chemotaxis and chemotactic factors: assay procedures. Clin. Immunol. Newsletter, $I:$ I (1980)

20. Malech, H. L., Root, R. K., and Gallin, J. I.: Structural analysis of human neutrophil migration. Centriole, microtubule, and microfilament orientation and function during chemotaxis. J. Cell. Biol., 75: 666 (1977).

21. Nelson, R., Quie, P. G., and Simmons, R. L.: Chemotaxis under agarose: a new and simple method for measuring chemotaxis and spontaneous migration of human polymorphonuclear leucocytes and monocytes. J. Immunol., 115: 1659 (1975).

22. Oster, J., Mikkelsen, M., and Nielsen, A.: Mortality and life-table in Down's syndrome. Acta Pediatr. Scand., 64: 322 (1975).

23. Everson-Pears, A. G.: Histochemistry, Theoretical and Applied. II. pp 1305, 1334 (Appendix 17 and 17). Churchill Livingstone, Edinburgh, 1972).
24. Raab, S. O., Mellman, W. J., Oski, F. A., and Bake, D.: Abnormal leukocyte kinetics-an explanation for enzyme abnormalities observed in trisomy 21 (Down's syndrome). J. Pediatr., 69: 952 (1966).

25. Ramos-Galván, R.: Somatometría pedíatrica. Estudio semilongitudinal en niños de la ciudad de México. Arch. Invest. Med. (Mex.), 6: (Suppl. 1) (1975).

26. Rosenthal, A. S.: Regulation of the immune response. Role of the macrophage N. Engl. J. Med., 303: 1153 (1980).

27. Rosner, F., Kozinn, P. J., and Jervis, G. A.: Leucocyte function and serum immunoglobulins in Down's syndrome. N. Y. State J. Med., 73: 672 (1973).

28. Siegel, M.: Susceptibility of mongoloids to infection. Am. J. Hyg., 48: 53 (1948). 29. Siegel, S.: Nonparametric Statistics for the Behavioral Sceinces. pp. 116-127. (McGraw Hill Book Co. Inc., New York. 1956).

30. Stiehm, E. R. and Fudenberg, H. H.: Serum levels of immune globulins in health and disease. A survey. Pediatrics, 37: 715 (1966).

31. Tono-Oka, T., Nakayama, M., Uehara, H., and Matsumoto, S.: Characteristics of impaired chemotactic function in cord blood leukocytes. Pediatr. Res., 13 . 148 (1979).

32. Unanue, E. R.: Macrophage functions in immunity. Fed. Proc., 37: 77 (1978).

33. Ward, P. A.: Chemotaxis of mononuclear cells. J. Exper. Med., 128: 1201 (1968).

34. Whittingham, S., Pitt, D. B., Sharma, D. L. B., and Mackay, 1. R.: Stress deficiency of the T-lymphocyte system exemplified by Down syndrome. Lancet, $1: 163$ (1977)

35. Wilkinson, P. C.: Leucocyte locomotion and chemotaxis: effects of bacteria and viruses. Rev. Inf. Dis., 3: 293 (1980)

36. Zakhireh, B. and Malech, H. L.: The effect of colchicine and vinblastine on the chemotactic response of human monocytes. J. Immunol., 125: 2143 (1980).

37. The authors wish to thank Ms. Aida Enríquez and Ms. Rosa Delgado for their excellent secretarial help.

38. Requests for reprints should be addressed to: Dr. Roberto R. Kretschmer. Head Division of Immunology. Unidad de Investigación Científica, Centro Médico Nacional, I.M.S.S. Apartado Postal 73-032. México, D.F. 03020

39. Received for publication August 19, 1981.

40. Accepted for publication August 16, 1982 